\title{
Exosomes in the thymus: antigen transfer and vesicles
}

\author{
Gabriel Skogberg ${ }^{1 *}$, Esbjörn Telemo ${ }^{1}$ and Olov Ekwall ${ }^{1,2}$ \\ ${ }^{1}$ Department of Rheumatology and Inflammation Research, Institute of Medicine, The Sahlgrenska Academy, Gothenburg \\ University, Gothenburg, Sweden, ${ }^{2}$ Department of Pediatrics, Institute of Clinical Sciences, The Sahlgrenska Academy, \\ Gothenburg University, Gothenburg, Sweden
}

OPEN ACCESS

Edited by: Geraldo Aleixo Passos, University of São Paulo, Brazil

Reviewed by: Bin Li,

Chinese Academy of Sciences, China Nuno L. Alves, University of Porto, Portugal

*Correspondence:

Gabriel Skogberg,

Department of Rheumatology and Inflammation Research, Sahlgrenska Academy, University of Gothenburg,

Guldhedsgatan 10A, Gothenburg Västra Götaland, Gothenburg SE 405 30, Sweden xskoga@gu.se

Specialty section:

This article was submitted to Immunological Tolerance, a section of the journal Frontiers in Immunology

Received: 14 May 2015 Accepted: 06 July 2015

Published: 20 July 2015

Citation:

Skogberg G, Telemo E and Ekwall O (2015) Exosomes in the thymus: antigen transfer and vesicles. Front. Immunol. 6:366. doi: 10.3389/fimmu.2015.00366
Thymocytes go through several steps of maturation and selection in the thymus in order to form a functional pool of effector T-cells and regulatory T-cells in the periphery. Close interactions between thymocytes, thymic epithelial cells, and dendritic cells are of vital importance for the maturation, selection, and lineage decision of the thymocytes. One important question that is still unanswered is how a relatively small epithelial cell population can present a vast array of self-antigens to the manifold larger population of developing thymocytes in this selection process. Here, we review and discuss the literature concerning antigen transfer from epithelial cells with a focus on exosomes. Exosomes are nano-sized vesicles released from a cell into the extracellular space. These vesicles can carry proteins, microRNAs, and mRNAs between cells and are thus able to participate in intercellular communication. Exosomes have been shown to be produced by thymic epithelial cells and to carry tissue-restricted antigens and MHC molecules, which may enable them to participate in the thymocyte selection process.

Keywords: exosome, thymic epithelial cell, tolerance, tissue-restricted antigen, miRNA

\section{Introduction}

Exosomes are small $(30-100 \mathrm{~nm})$ vesicles released by cells into the extracellular space. They are a subgroup of extracellular vesicles (EVs) formed by inward budding of membranes in the late endosomes, thus creating a multi-vesicular body (MVB), which may dock to the outer membrane of the cell and release its content of exosomes $(1,2)$. In hindsight, the recycling of the transferrin receptor back to the cell membrane from an endocytic route in developing erythrocytes was the original description of exosomes in 1983 (3). One particularly striking finding, which in recent years has heavily influenced exosome research, was the identification of microRNA (miRNA) and mRNA in exosomes (4). Exosomal transfer of functional miRNA and mRNA has been demonstrated to result in regulation of gene expression through miRNA as well as translation of proteins through mRNA in recipient cells $(5,6)$. Exosomes are abundant in, and fairly easy to purify from, bodily fluids such as saliva (7), peripheral blood (8), bronco alveolar lavage fluid (9), and urine (10,11), and one area of extensive research is the use of exosomes as diagnostic biomarkers for various pathologic conditions (12).

Exosomes have also shown therapeutic promise, e.g., in a study by Zitvogel and co-workers it was demonstrated that tumor peptide-pulsed dendritic cells (DCs) released exosomes that carried MHC I and II as well as co-stimulatory molecules and that these exosomes primed cytotoxic T-cells and suppressed the growth of established tumors (13). Native antigens on tumor-derived exosomes can be taken up by DCs and cross-presented to tumor-specific cytotoxic T-cells (14).

Other studies have revealed that exosomes are capable of presenting antigens to T-cells. In 1996, Raposo et al. (15) reported that both human and murine B-cell derived exosomes could induce an 
antigen-specific MHC II-restricted T-cell response. Exosome-like structures, named tolerosomes, are released from epithelial cells of the small intestine and have been shown to induce specific tolerance to fed antigens (16). As with the B-cell derived exosomes, tolerosomes seem to deliver antigens in a MHC dependent manner (17).

The thymus is the organ responsible for the establishment of an immune competent but yet self-tolerant T-cell population. While the extreme diversity of the mature effector T-cell specificities is a prerequisite for an effective defense against invading pathogens/infectious agents, the negative selection of self-reactive effector T-cells and the positive selection of $\mathrm{T}$ regulatory cells ensure tolerance to self-structures in order to avoid autoimmunity. To ensure a self-tolerant peripheral population, thymocytes are selected against a comprehensive set of self-antigens (18) of which many are produced and presented by medullary thymic epithelial cells (mTECs) (19) under control of the autoimmune regulator (AIRE) (20). The importance of a functional thymic antigen expression has been validated in models where even a defect expression of a single antigen may lead to development of peripheral organ-specific autoimmunity (21). Of equal importance is the selection of regulatory T-cells (Tregs) within the thymus, foremost from clones with a somewhat elevated TCR avidity for self-antigens (22). Proper thymic Treg development is also dependent on AIRE, and in particular for the functionally important Tregs that are induced during the perinatal period (23).

Since thymocytes outnumber TECs by several orders of magnitude, and the fact that each individual TEC only expresses a small subgroup of self-antigens $(18,24)$, a possible dissemination of antigen from TECs has been discussed in order to aid individual TECs to cover an extended volume of the thymic microenvironment (25). This would increase the number of possible antigen-thymocyte interactions and allow additional impact of the thymic DC populations. Antigen transfer could potentially occur by different means such as apoptotic bodies, nanotubes, and/or exosomes. Here, we review the current literature and argue that thymic exosomes have a potential role in T-cell maturation and selection.

\section{Antigen Transfer and Indirect Antigen Presentation in the Thymus}

Clearly, direct cell-cell contacts in the thymus are pivotal for the development of a functional T-cell population (26). The addition of antigen transfer between thymic cell populations could, however, optimize thymic cell communication by making antigens more available to the pool of developing thymocytes. Through the last two decades, a number of studies performed under different experimental conditions have demonstrated the transfer of antigens from TECs to DCs. Already in 1994, Kyewski and co-workers observed intercellular transfer of $E \alpha_{52-68}$ (a-chain of the MHC class II allele I-E $\mathrm{E}^{\mathrm{d}}$, amino acids 52-68) from TECs to thymic DCs in a unidirectional fashion (27). They proposed that this mechanism "may enhance the efficacy of tolerance induction by spreading self-antigens" (27). Subsequent experiments with
OVA-specific TCR-transgenic mice (RIP-mOVA model) revealed that transfer of antigen to and presentation by hematopoietic cells also applies to MHC class I-restricted epitopes, since it resulted in deletion of both MHC class I- and MHC class II-restricted OVAspecific thymocytes when OVA was expressed only by mTECs (28). The identity of the hematopoietic cells in the RIP-mOVA study was unclear but further studies have revealed that deletion of CD11c+ cells using CD11c-Cre mice crossed with mice expressing diphtheria toxin under the control Rosa Locus containing a loxP-flanked STOP cassette results in increased frequencies of CD4+ thymocytes and increased CD4 T-cell infiltration into peripheral tissues (29). Likewise, Aschenbrenner and colleagues have observed that DCs capture mTEC-derived antigens and take part in deletional tolerance (30). This observation was strengthened by a study by Koble and Kyewski who demonstrated a presentation of TEC antigens by DCs. In their study, thymic but not peripheral DCs presented TEC-derived OVA to OVA-specific T-cells and were constitutively provided with mTEC-derived proteins (31). Further, unidirectional antigen transfer from mTEC to DCs was shown to also apply for native endogenous selfantigens in vivo (31). Non-redundant contribution of DCs and mTECs is further suggested based on simultaneous hematopoietic MHC class II deficiency and reduced MHC II expression on mTECs; this combination has an additive worsening effect on negative selection compared to either of the single deficiencies alone (32).

Also, the Treg formation seem to be dependent of DC-TEC cross-talk, which was elegantly demonstrated in a study on bone marrow chimeras in which CD28/B7 signaling was disrupted on either hematopoietic-derived antigen-presenting cells (APCs) or on TECs. The results showed that when B7 was restored in the hematopoietic-derived APCs this was enough to restore Treg numbers, hence hematopoietic-derived APCs and TECs can independently contribute to Treg development (33). The transfer of material in this study was unidirectional toward DCs, and the discussed mechanisms were primarily exosomes and apoptotic bodies. Transfer of material from TECs to DCs has also been demonstrated in the work by Hubert and co-workers in which OT-II restricted thymocytes were deleted by a soluble form of OVA that required presentation by bone marrow-derived cells (34). Using tetramer staining and transfer of bone marrow with ablated expression of MHC II, Taniguchi and co-workers found an abolished negative selection of T-cells specific for the AIRE-controlled self-antigen retinoid-binding protein (35). They concluded that intercellular transfer of the interphotoreceptor retinoid-binding protein peptide epitope of amino acids 277-290 from AIRE-expressing mTECs to bone marrow-derived APCs is important for negative selection of the investigated peptide. In reaggregated thymic organ cultures, both the thymic epithelium and conventional DCs (as opposed to plasmacytoid DCs) have been shown capable of eliminating autoreactive CD4 thymocytes and to support natural Treg (nTreg) development on their own (36). In addition, Perry and co-workers recently reported that CD8 $\alpha+$ DCs preferentially acquire and present AIRE-dependent antigens to developing Treg cells (37). They also showed that bone marrowderived APCs and mTECs play non-overlapping roles in shaping 
of the T-cell receptor repertoire in terms of deletion and Treg selection (37).

\section{T-Cell Stimulation by Exosomes, With or Without DCs}

The capacity of exosomes to directly stimulate target cells has been debated. Some studies have suggested that there is an absolute need for DC presence for efficient exosomal stimulation of Tcells (38-40), while others have shown that exosomes are able to directly stimulate T-cells without any aid from DCs $(15,41-$ 44). Models in which the efficiency of exosomal T-cell stimulation increases by DC presence have also been put forward (45). Interestingly, thymic exosomes carry ICAM-1 (46), which is both required for efficient T-cell responses (40) and involved in exosome binding to DCs (47). In addition to ICAM-1, thymus exosomes carry the opsonin MFGE8, which indicates that thymic exosomes would readily be engulfed by APCs such as DCs (46). TEC exosomes are also strongly positive for HLA-DR, which suggest a possibility that they contribute with antigens not only indirectly via, e.g., DCs but also directly to developing thymocytes (48). The presence of co-stimulatory molecules on exosomes may be important for their potential to affect the maturation of nTreg precursors (49). However, whether TEC exosomes that carry antigen presentation molecules and antigens need APCs or not to participate in thymocyte selection in vivo is not known. Possibly, thymic exosomes could take part in negative selection both directly by interacting with the thymocytes or indirectly by delivering antigens to APCs such as thymic DCs (Figures 1A,B).

\section{Characteristics of Thymic Exosomes}

The first observation of exosome-like structures in thymic tissue was made by Wang and co-workers (50). These mouse thymic exosomes were characterized by high content of TGF-beta, CD9, and MHC II. In human beings, thymic exosomes were originally characterized with the use of explant cultures (46). The thymic exosomes shared features with exosomes from other sources, such as a size distribution of $30-100 \mathrm{~nm}$ for a majority of the vesicles, density peaking at $1.18-1.19 \mathrm{~g} / \mathrm{ml}$, which is less than the typical density of histone dense apoptotic bodies (51), and presence of typical exosomal proteins such as TSG101, CD9, CD81, and HLADR. Since these thymic exosomes were isolated from whole thymic tissue, the cellular source could not be determined, and the vesicles were most probably a mix of exosomes from different sources, e.g., thymocytes, TECs, and DCs. Even so, tissue-restricted antigens (TRAs), defined by protein-expression allowed in a maximum of five tissues in the human protein atlas (HPA) (52) were identified in the exosomes $\left(2^{\prime}, 3^{\prime}\right.$-cyclic-nucleotide $3^{\prime}$ phosphodiesterase, reticulon 3 , tropomyosin 3 , and the GNAS protein), which suggest that a portion of the exosomes originates from the thymic epithelium (46). These four identified TRAs are possible candidates to participate in the selection/maturation processes within the human thymus. With the exception of one study that address thymic expression of $2^{\prime}, 3^{\prime}$-cyclic-nucleotide $3^{\prime}$ phosphodiesterase (53), the four TRAs are hitherto unaddressed in thymic research. Interestingly, $2^{\prime}, 3^{\prime}$-cyclic-nucleotide $3^{\prime}$ phosphodiesterase is recognized by IgG autoantibodies in multiple sclerosis patients (54).
In addition, tropomyosin 3 was suggested to be a candidate antigen in endometriosis (55).

Other traits seem to be specific for thymic exosomes compared to exosomes from other sources. One is the massive yield of $\sim 1 \mathrm{mg}$ of thymic exosomes per gram of thymic tissue grown in an explant culture (46). Other characteristics typical for thymic exosomes are the low expression of CD63 and the high expression of TSG101 on their surface (46). However, low levels of CD63 could have functional implications for thymic exosomes since it has been reported that siRNA mediated knockdown of the tetraspanin CD63 in a B-lymphoblastoid cell line (LCL) resulted in an increased CD4 + T-cell recognition as evaluated by IFN- $\gamma$ production. The increase in T-cell response could not be explained by changes in antigen processing or MHC II-expression (56). Instead, equal amounts of exosomes from CD63 ${ }^{\text {low }}$ LCL cells and control LCL cells stimulated the T-cells to comparable degrees, but the CD63 ${ }^{\text {low }}$ LCL cells produced more exosomes, which in the end enhanced the total T-cell-stimulatory capacity of the CD $63^{\text {low }}$ LCL cells.

Formal proof that TECs are able to produce exosomes was provided with the use of an approach in which primary cultures of TECs were established under selective conditions to eliminate the presence of thymocytes, DCs, fibroblasts, and peripherally produced exosomes $(48,57)$. The results showed that TECs produce exosomes and that these exosomes contained TRAs and number of known autoantigens (48). Among the identified autoantigens in TEC exosomes were myelin basic protein (58), collagen type II (59), TITIN (60), heat shock protein 60 [connected with various autoimmune diseases (61)], transglutaminase 2 (62), desmoglein 1 , and desmoglein 3 (63). In addition to autoantigens, previously reported mTEC-enriched TRAs were present in TEC exosomes, e.g., glutathione S-transferase M3 (GSTM3), LDL receptor, monocarboxylate transporter 4 (SLC16A3), mucins (MUC5B and MUC18), and myosin 1B (MYO1B) (48).

The observation that TEC exosomes have a higher fraction of proteins classified as TRAs (24\%) compared to the fraction of TRAs in the cultured TECs (21\%) could argue for a directed loading of TRAs into the exosomes (48).

Exosomes isolated directly from thymic tissue and exosomes isolated from TEC-cultures share a set of TRAs, such as $2^{\prime}, 3^{\prime}$ cyclic-nucleotide $3^{\prime}$ phosphodiesterase, which strengthens that thymic explant exosomes are partly of epithelial origin and that their TRA-content can be analyzed with whole thymic tissue as starting material. See Figure 1C for a schematic summary of the TEC-exosomal proteome. In addition, the presence of antigenpresenting molecules together with TRAs indicates that exosomes could transfer intact functional peptide-MHC complexes.

\section{RNA Transfer by Exosomes}

Exosomes have been increasingly recognized for their ability to transfer functional miRNAs and mRNAs between cells (4), and recently, it was shown that Tregs utilize exosomes for transfer of miRNA in order to functionally silence effector T-cells (64). The importance of miRNAs in the thymus has rendered an increased interest, and miRNAs have been shown to affect promiscuous gene expression under the influence of $\operatorname{AIRE}(65,66)$, to be involved in 
A
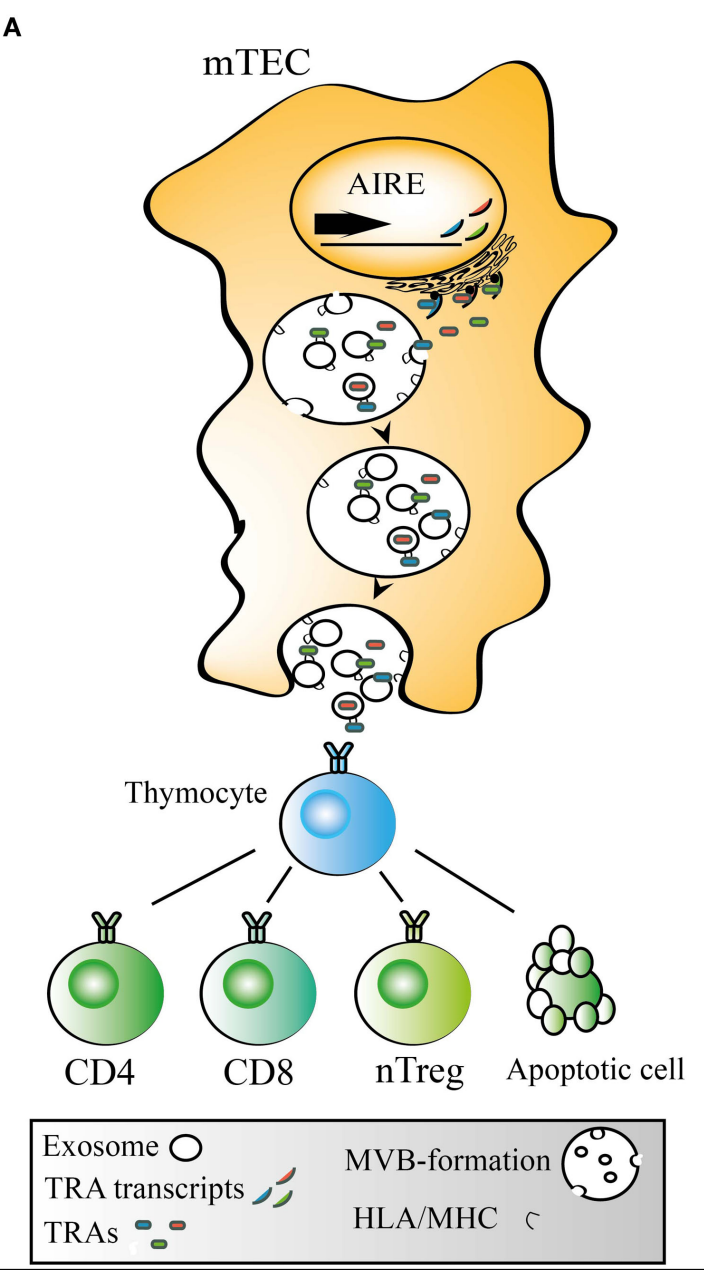

c

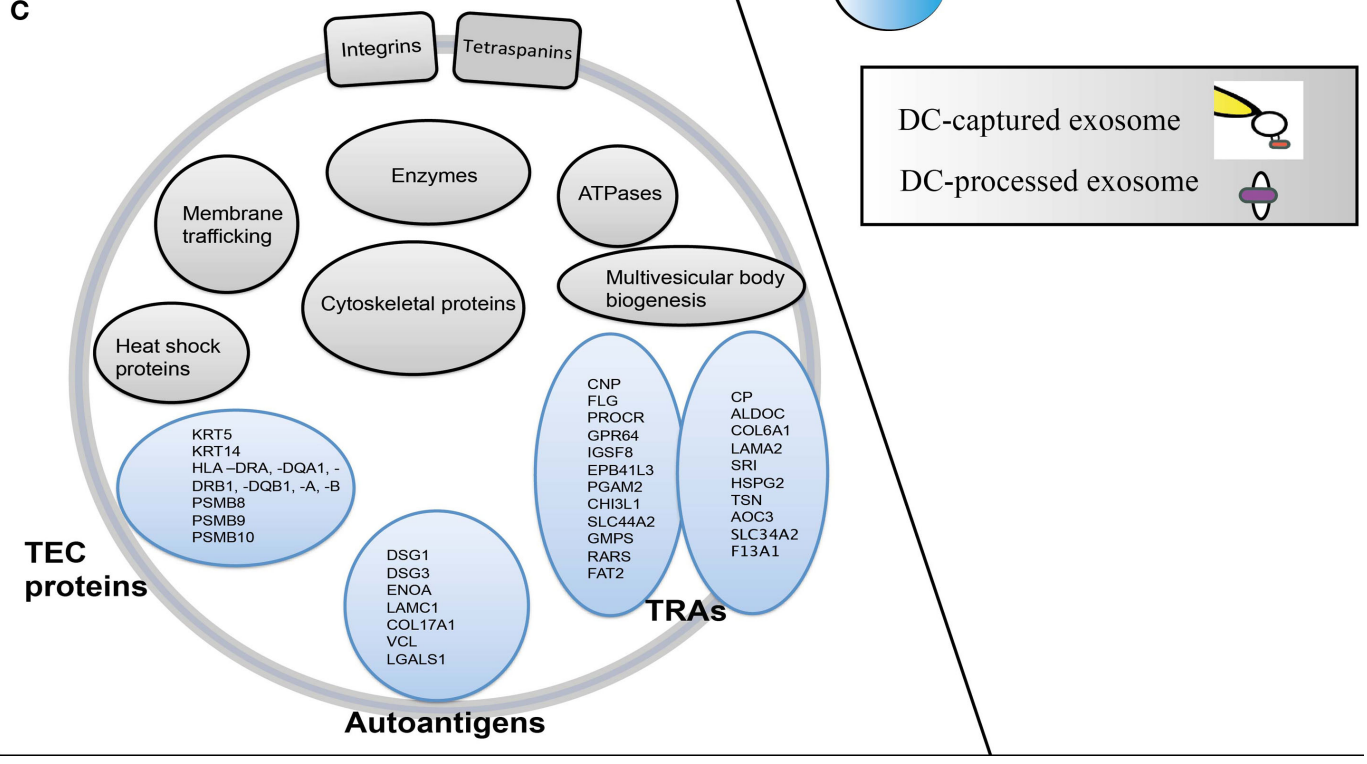

FIGURE 1 | Models for transfer of exosomal material from TECs to other thymic cell populations. Transcription and translation of AIRE-dependent TRAs followed by TRA loading of exosomes, MVB fusion with the MTEC plasma membrane leading to exosome release from mTECs. The exosomes could then take an intercellular route from mTECs directly (A) to CD4+, CD8+, and developing $n$ Tregs and/or indirectly (B) via thymic DC or other APCs. (C) The proteome of thymic exosomes typically include exosomal markers, e.g., tetraspanins, TEC associated proteins, TRAs, and autoantigens $(46,48)$. 


\section{A}
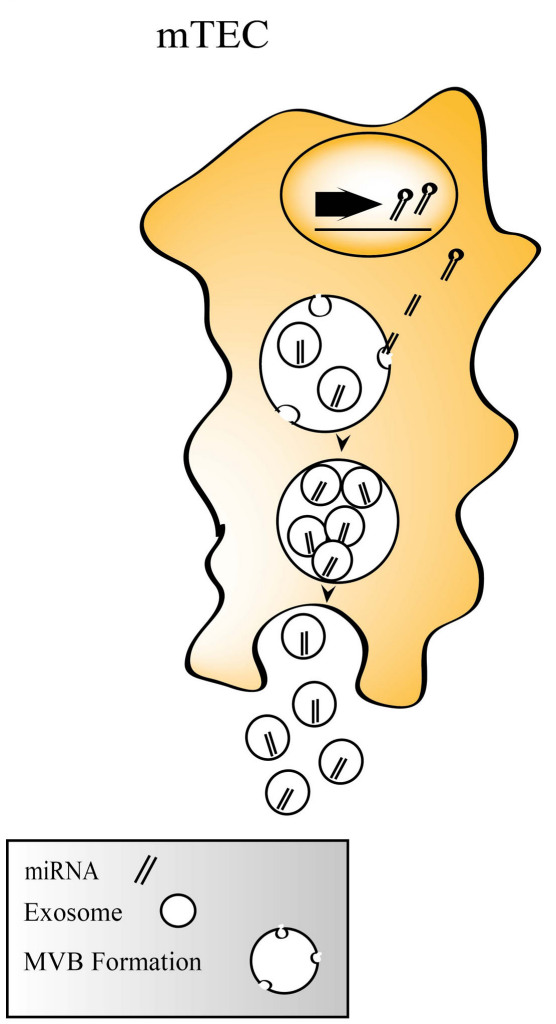

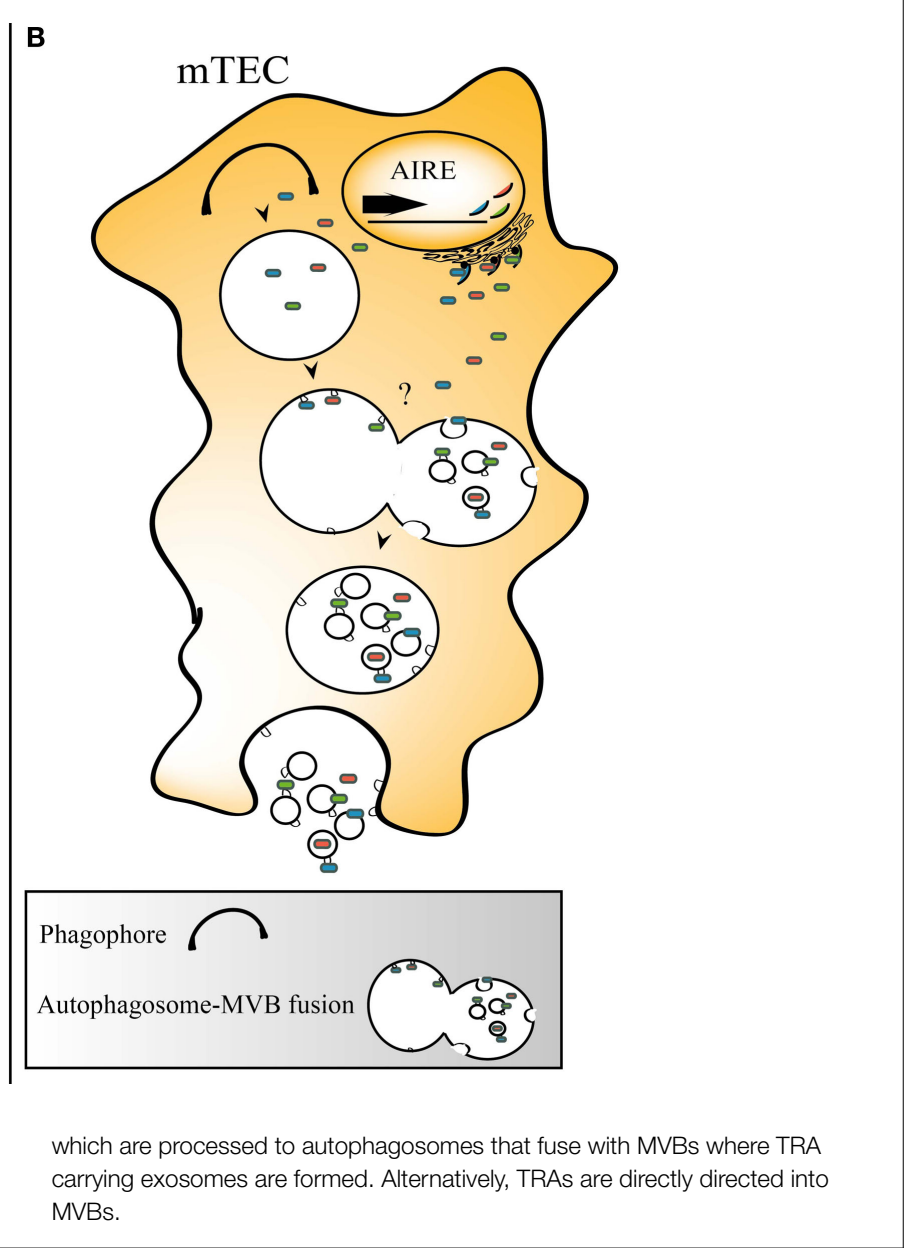

protein $\mathrm{C}$ terminus in pancreatic cancer cell lines (73). Exosomal release is also impaired in mouse embryonic fibroblasts lacking ATG12-ATG3, and immature autophagosomes are shown to fuse with MVBs in these cells (74). Whether this also occurs in TECs is so far unaddressed, but this route could potentially make antigens that are processed in the autophagic machinery available for export on exosomes and at the same time enhance the loading of endogenous antigens onto MHC class II molecules (Figure 2B).

\section{Concluding Remarks}

Tissue-restricted antigen presentation within the thymic micromileus is pivotal to establish central tolerance. Antigen transfer between thymic cell populations, e.g., from mTECs to thymocytes and DCs is an established phenomenon that is poorly investigated from a mechanistic point of view. To get a more comprehensive understanding of central tolerance, the role of antigen transfer and the responsible vectors, e.g., exosomes, need to be studied and understood in more depth.

The abundant presence of TRA-containing exosomes in thymic tissue and the many observations of antigen transfer from mTECs to DCs lead us to speculate that this antigen transfer is, at least partly, mediated by exosomes. However, such a mechanism has not yet been formally proven. Although this review has been focused on possible antigen transfer by mTEC-derived exosomes 
to DCs and thymocytes, it is not excluded that also cTECs produce exosomes and that exosomes are shuttling antigens between different TEC populations. Other questions also remain regarding thymic exosomes that are equally important to answer in future studies; do exosomes exist in vivo in enough quantities to be biologically functional in the context of tolerance induction? If so, which is the primary route, direct interaction with thymocytes or indirect via APCs? What is the importance of exosomes for nTreg induction? Also, does miRNA content of the exosomes affect the development and maturation of thymic cells? Examples of experimental approaches that could be used to address these questions

\section{References}

1. Fevrier B, Raposo G. Exosomes: endosomal-derived vesicles shipping extracellular messages. Curr Opin Cell Biol (2004) 16:415-21. doi:10.1016/j.ceb.2004. 06.003

2. Kalra H, Simpson RJ, Ji H, Aikawa E, Altevogt P, Askenase P, et al. Vesiclepedia: a compendium for extracellular vesicles with continuous community annotation. PLoS Biol (2012) 10:e1001450. doi:10.1371/journal.pbio.1001450

3. Harding C, Heuser J, Stahl P. Receptor-mediated endocytosis of transferrin and recycling of the transferrin receptor in rat reticulocytes. J Cell Biol (1983) 97:329-39. doi:10.1083/jcb.97.2.329

4. Valadi H, Ekström K, Bossios A, Sjostrand M, Lee JJ, Lotvall JO. Exosomemediated transfer of mRNAs and microRNAs is a novel mechanism of genetic exchange between cells. Nat Cell Biol (2007) 9:654-9. doi:10.1038/ncb1596

5. Pegtel DM, Cosmopoulos K, Thorley-Lawson DA, Van Eijndhoven MA, Hopmans ES, Lindenberg JL, et al. Functional delivery of viral miRNAs via exosomes. Proc Natl Acad Sci U S A (2010) 107:6328-33. doi:10.1073/pnas. 0914843107

6. Ridder K, Keller S, Dams M, Rupp AK, Schlaudraff J, Turco DD, et al. Extracellular vesicle-mediated transfer of genetic information between the hematopoietic system and the brain in response to inflammation. PLoS Biol (2014) 12(6):e1001874. doi:10.1371/journal.pbio.1001874

7. Michael A, Bajracharya SD, Yuen PS, Zhou H, Star RA, Illei GG, et al. Exosomes from human saliva as a source of microRNA biomarkers. Oral Dis (2010) 16:34-8. doi:10.1111/j.1601-0825.2009.01604.x

8. Caby MP, Lankar D, Vincendeau-Scherrer C, Raposo G, Bonnerot C. Exosomallike vesicles are present in human blood plasma. Int Immunol (2005) 17:879-87. doi:10.1093/intimm/dxh267

9. Admyre C, Grunewald J, Thyberg J, Gripenback S, Tornling G, Eklund A, et al. Exosomes with major histocompatibility complex class II and co-stimulatory molecules are present in human BAL fluid. Eur Respir J (2003) 22:578-83. doi:10.1183/09031936.03.00041703

10. Kanno K, Sasaki S, Hirata Y, Ishikawa S, Fushimi K, Nakanishi S, et al. Urinary excretion of aquaporin-2 in patients with diabetes insipidus. NEngl J Med (1995) 332:1540-5. doi:10.1056/NEJM199506083322303

11. Pisitkun T, Shen RF, Knepper MA. Identification and proteomic profiling of exosomes in human urine. Proc Natl Acad Sci U S A (2004) 101:13368-73. doi:10.1073/pnas.0403453101

12. Taylor DD, Gercel-Taylor C. MicroRNA signatures of tumor-derived exosomes as diagnostic biomarkers of ovarian cancer. Gynecol Oncol (2008) 110:13-21. doi:10.1016/j.ygyno.2008.04.033

13. Zitvogel L, Regnault A, Lozier A, Wolfers J, Flament C, Tenza D, et al. Eradication of established murine tumors using a novel cell-free vaccine: dendritic cell-derived exosomes. Nat Med (1998) 4:594-600. doi:10.1038/nm0598-594

14. Wolfers J, Lozier A, Raposo G, Regnault A, Thery C, Masurier C, et al. Tumorderived exosomes are a source of shared tumor rejection antigens for CTL cross-priming. Nat Med (2001) 7:297-303. doi:10.1038/85438

15. Raposo G, Nijman HW, Stoorvogel W, Liejendekker R, Harding CV, Melief CJ, et al. B lymphocytes secrete antigen-presenting vesicles. J Exp Med (1996) 83:1161-72. doi:10.1084/jem.183.3.1161

16. Karlsson M, Lundin S, Dahlgren U, Kahu H, Pettersson I, Telemo E. “Tolerosomes" are produced by intestinal epithelial cells. Eur J Immunol (2001) 31:2892-900. doi:10.1002/1521-4141(2001010)31:10<2892::AID-IMMU2892> 3.0.CO;2-I are TEC specific inhibition of the ESCRT machinery using the FOXN1-cre system or microinjection of thymic exosomes isolated from wild type mice into $\mathrm{AIRE}^{-1-}$ thymii. The outcome of this kind of experiments may give hints to whether a therapeutic use of tailor made exosomes to induce antigen-specific tolerance may be possible in the future.

\section{Acknowledgments}

OE was supported by the Marianne and Marcus Wallenberg Foundation (MMW 2012.0052).

17. Ostman S, Taube M, Telemo E. Tolerosome-induced oral tolerance is MHC dependent. Immunology (2005) 116:464-76. doi:10.1111/j.1365-2567.2005. 02245.x

18. Sansom SN, Shikama-Dorn N, Zhanybekova S, Nusspaumer G, Macaulay IC, Deadman ME, et al. Population and single-cell genomics reveal the Aire dependency, relief from Polycomb silencing, and distribution of self-antigen expression in thymic epithelia. Genome Res (2014) 24:1918-31. doi:10.1101/gr. 171645.113

19. Derbinski J, Schulte A, Kyewski B, Klein L. Promiscuous gene expression in medullary thymic epithelial cells mirrors the peripheral self. Nat Immunol (2001) 2:1032-9. doi:10.1038/ni723

20. Anderson MS, Venanzi ES, Klein L, Chen Z, Berzins SP, Turley SJ, et al. Projection of an immunological self shadow within the thymus by the aire protein. Science (2002) 298:1395-401. doi:10.1126/science.1075958

21. Chentoufi AA, Polychronakos C. Insulin expression levels in the thymus modulate insulin-specific autoreactive T-cell tolerance: the mechanism by which the IDDM2 locus may predispose to diabetes. Diabetes (2002) 51:1383-90. doi:10.2337/diabetes.51.5.1383

22. Lio CW, Hsieh CS. Becoming self-aware: the thymic education of regulatory $\mathrm{T}$ cells. Curr Opin Immunol (2011) 23(2):213-9. doi:10.1016/j.coi.2010.11.010

23. Yang S, Fujikado N, Kolodin D, Benoist C, Mathis D. Regulatory T cells generated early in life play a distinct role in maintaining self-tolerance. Science (2015) 348:589-94. doi:10.1126/science.aaa7017

24. Derbinski J, Pinto S, Rosch S, Hexel K, Kyewski B. Promiscuous gene expression patterns in single medullary thymic epithelial cells argue for a stochastic mechanism. Proc Natl Acad Sci U S A (2008) 105:657-62. doi:10.1073/pnas. 0707486105

25. Kyewski B, Feuerer M. Love is in the Aire: mTECs share their assets. Immunity (2014) 41:343-5. doi:10.1016/j.immuni.2014.08.013

26. Klein L, Hinterberger M, Von Rohrscheidt J, Aichinger M. Autonomous versus dendritic cell-dependent contributions of medullary thymic epithelial cells to central tolerance. Trends Immunol (2011) 32(5):188-93. doi:10.1016/j.it.2011. 03.002

27. Humblet C, Rudensky AY, Kyewski B. Presentation and intercellular transfer of self antigen within the thymic microenvironment: expression of the E alpha peptide-I-Ab complex by isolated thymic stromal cells. Int Immunol (1994) 6(12):1949-58. doi:10.1093/intimm/6.12.1949

28. Gallegos AM, Bevan MJ. Central tolerance to tissue-specific antigens mediated by direct and indirect antigen presentation. J Exp Med (2004) 200:1039-49. doi:10.1084/jem.20041457

29. Ohnmacht C, Pullner A, King SB, Drexler I, Meier S, Brocker T, et al. Constitutive ablation of dendritic cells breaks self-tolerance of CD4 T cells and results in spontaneous fatal autoimmunity. J Exp Med (2009) 206:549-59. doi:10.1084/ jem.20082394

30. Aschenbrenner K, D'cruz LM, Vollmann EH, Hinterberger M, Emmerich J, Swee LK, et al. Selection of Foxp3+ regulatory $\mathrm{T}$ cells specific for self antigen expressed and presented by Aire+ medullary thymic epithelial cells. Nat Immunol (2007) 8:351-8. doi:10.1038/ni1444

31. Koble C, Kyewski B. The thymic medulla: a unique microenvironment for intercellular self-antigen transfer. J Exp Med (2009) 206:1505-13. doi:10.1084/ jem.20082449

32. Hinterberger M, Aichinger M, Prazeres Da Costa O, Voehringer D, Hoffmann R, Klein L. Autonomous role of medullary thymic epithelial cells in central CD4(+) T cell tolerance. Nat Immunol (2010) 11:512-9. doi:10.1038/ni.1874 
33. Roman E, Shinom H, Qin FX, Liu YJ. Cutting edge: hematopoietic-derived APCs select regulatory T cells in thymus. J Immunol (2010) 185:3819-23. doi:10.4049/jimmunol.0900665

34. Hubert FX, Kinkel SA, Davey GM, Phipson B, Mueller SN, Liston A, et al. Aire regulates the transfer of antigen from mTECs to dendritic cells for induction of thymic tolerance. Blood (2011) 118:2462-72. doi:10.1182/ blood-2010-06-286393

35. Taniguchi RT, Devoss JJ, Moon JJ, Sidney J, Sette A, Jenkins MK, et al. Detection of an autoreactive T-cell population within the polyclonal repertoire that undergoes distinct autoimmune regulator (Aire)-mediated selection. Proc Natl Acad Sci U S A (2012) 109:7847-52. doi:10.1073/pnas.1120607109

36. Guerri L, Peguillet I, Geraldo Y, Nabti S, Premel V, Lantz O. Analysis of APC types involved in CD4 tolerance and regulatory T cell generation using reaggregated thymic organ cultures. J Immunol (2013) 190:2102-10. doi:10. 4049/jimmunol.1202883

37. Perry JS, Lio CW, Kau AL, Nutsch K, Yang Z, Gordon JI, et al. Distinct contributions of aire and antigen-presenting-cell subsets to the generation of selftolerance in the thymus. Immunity (2014) 41:414-26. doi:10.1016/j.immuni. 2014.08.007

38. Thery C, Duban L, Segura E, Veron P, Lantz O, Amigorena S. Indirect activation of naive CD4+ T cells by dendritic cell-derived exosomes. Nat Immunol (2002) 3:1156-62. doi:10.1038/ni854

39. Vincent-Schneider H, Stumptner-Cuvelette P, Lankar D, Pain S, Raposo G, Benaroch P, et al. Exosomes bearing HLA-DR1 molecules need dendritic cells to efficiently stimulate specific T cells. Int Immunol (2002) 14:713-22. doi:10. 1093/intimm/dxf048

40. Segura E, Nicco C, Lombard B, Veron P, Raposo G, Batteux F, et al. ICAM1 on exosomes from mature dendritic cells is critical for efficient naive T-cell priming. Blood (2005) 106:216-23. doi:10.1182/blood-2005-01-0220

41. Sprent J. Direct stimulation of naive T cells by antigen-presenting cell vesicles. Blood Cells Mol Dis (2005) 35(1):17-20. doi:10.1016/j.bcmd.2005.04.004

42. Admyre C, Johansson SM, Paulie S, Gabrielsson S. Direct exosome stimulation of peripheral human T cells detected by ELISPOT. Eur J Immunol (2006) 36:1772-81. doi:10.1002/eji.200535615

43. Admyre C, Bohle B, Johansson SM, Focke-Tejkl M, Valenta R, Scheynius A, et al. $\mathrm{B}$ cell-derived exosomes can present allergen peptides and activate allergenspecific T cells to proliferate and produce TH2-like cytokines. J Allergy Clin Immunol (2007) 120:1418-24. doi:10.1016/j.jaci.2007.06.040

44. Nolte-'t Hoen EN, Buschow SI, Anderton SM, Stoorvogel W, Wauben MH. Activated T cells recruit exosomes secreted by dendritic cells via LFA-1. Blood (2009) 113:1977-81. doi:10.1182/blood-2008-08-174094

45. Utsugi-Kobukai S, Fujimaki H, Hotta C, Nakazawa M, Minami M. MHC class I-mediated exogenous antigen presentation by exosomes secreted from immature and mature bone marrow derived dendritic cells. Immunol Lett (2003) 89:125-31. doi:10.1016/S0165-2478(03)00128-7

46. Skogberg G, Gudmundsdottir J, Van Der Post S, Sandstrom K, Bruhn S, Benson M, et al. Characterization of human thymic exosomes. PLoS One (2013) 8:e67554. doi:10.1371/journal.pone.0067554

47. Segura E, Guerin C, Hogg N, Amigorena S, Thery C. CD8+ dendritic cells use LFA-1 to capture MHC-peptide complexes from exosomes in vivo. J Immunol (2007) 179:1489-96. doi:10.4049/jimmunol.179.3.1489

48. Skogberg G, Lundberg V, Berglund M, Gudmundsdottir J, Telemo E, Lindgren $S$, et al. Human thymic epithelial primary cells produce exosomes carrying tissue-restricted antigens. Immunol Cell Biol (2015). doi:10.1038/icb. 2015.33

49. Hinterberger M, Wirnsberger G, Klein L. B7/CD28 in central tolerance: costimulation promotes maturation of regulatory $\mathrm{T}$ cell precursors and prevents their clonal deletion. Front Immunol (2011) 2:30. doi:10.3389/fimmu.2011.00030

50. Wang GJ, Liu Y, Qin A, Shah SV, Deng ZB, Xiang X, et al. Thymus exosomeslike particles induce regulatory T cells. J Immunol (2008) 181:5242-8. doi:10. 4049/jimmunol.181.8.5242

51. Thery C, Boussac M, Veron P, Ricciardi-Castagnoli P, Raposo G, Garin J, et al. Proteomic analysis of dendritic cell-derived exosomes: a secreted subcellular compartment distinct from apoptotic vesicles. J Immunol (2001) 166:7309-18. doi:10.4049/jimmunol.166.12.7309

52. Uhlen M, Oksvold P, Fagerberg L, Lundberg E, Jonasson K, Forsberg M, et al. Towards a knowledge-based Human Protein Atlas. Nat Biotechnol (2010) 28:1248-50. doi:10.1038/nbt1210-1248
53. Bernier L, Alvarez F, Norgard EM, Raible DW, Mentaberry A, Schembri JG, et al. Molecular cloning of a 2',3'-cyclic nucleotide 3'-phosphodiesterase: mRNAs with different 5 ' ends encode the same set of proteins in nervous and lymphoid tissues. J Neurosci (1987) 7:2703-10.

54. Lovato L, Cianti R, Gini B, Marconi S, Bianchi L, Armini A, et al. Transketolase and 2',3'-cyclic-nucleotide 3'-phosphodiesterase type I isoforms are specifically recognized by IgG autoantibodies in multiple sclerosis patients. Mol Cell Proteomics (2008) 7:2337-49. doi:10.1074/mcp.M700277-MCP200

55. Gajbhiye R, Sonawani A, Khan S, Suryawanshi A, Kadam S, Warty N, et al. Identification and validation of novel serum markers for early diagnosis of endometriosis. Hum Reprod (2012) 27:408-17. doi:10.1093/humrep/ der410

56. Petersen SH, Odintsova E, Haigh TA, Rickinson AB, Taylor GS, Berditchevski F. The role of tetraspanin CD63 in antigen presentation via MHC II. Eur J Immunol (2011) 41:2556-61. doi:10.1002/eji.201141438

57. Ropke C. Thymic epithelial cell culture. Microsc Res Tech (1997) 38: 276-86. doi:10.1002/(SICI)1097-0029(19970801)38:3<276::AID-JEMT8>3.3. CO;2-6

58. Allegretta M, Nicklas JA, Sriram S, Albertini RJ. T cells responsive to myelin basic protein in patients with multiple sclerosis. Science (1990) 247:718-21. doi:10.1126/science.1689076

59. Terato K, Shimozuru Y, Katayama K, Takemitsu Y, Yamashita I, Miyatsu M, et al. Specificity of antibodies to type II collagen in rheumatoid arthritis. Arthritis Rheum (1990) 33:1493-500. doi:10.1002/art.1780331006

60. Chen XJ, Qiao J, Xiao BG, Lu CZ. The significance of titin antibodies in myasthenia gravis - correlation with thymoma and severity of myasthenia gravis. J Neurol (2004) 251:1006-11. doi:10.1007/s00415-004-0479-z

61. Mallard K, Jones DB, Richmond J, Mcgill M, Foulis AK. Expression of the human heat shock protein 60 in thyroid, pancreatic, hepatic and adrenal autoimmunity. J Autoimmun (1996) 9:89-96. doi:10.1006/jaut.1996.0011

62. Dieterich W, Ehnis T, Bauer M, Donner P, Volta U, Riecken EO, et al. Identification of tissue transglutaminase as the autoantigen of celiac disease. Nat Med (1997) 3:797-801. doi:10.1038/nm0797-797

63. Amagai M, Klaus-Kovtun V, Stanley JR. Autoantibodies against a novel epithelial cadherin in pemphigus vulgaris, a disease of cell adhesion. Cell (1991) 67:869-77. doi:10.1016/0092-8674(91)90360-B

64. Okoye IS, Coomes SM, Pelly VS, Czieso S, Papayannopoulos V, Tolmachova $\mathrm{T}$, et al. MicroRNA-containing T-regulatory-cell-derived exosomes suppress pathogenic T helper 1 cells. Immunity (2014) 41:89-103. doi:10.1016/j.immuni. 2014.05.019

65. Macedo C, Evangelista AF, Marques MM, Octacilio-Silva S, Donadi EA, Sakamoto-Hojo ET, et al. Autoimmune regulator (Aire) controls the expression of microRNAs in medullary thymic epithelial cells. Immunobiology (2013) 218:554-60. doi:10.1016/j.imbio.2012.06.013

66. Ucar O, Tykocinski LO, Dooley J, Liston A, Kyewski B. An evolutionarily conserved mutual interdependence between Aire and microRNAs in promiscuous gene expression. Eur J Immunol (2013) 43(7):1769-78. doi:10.1002/eji. 201343343

67. Papadopoulou AS, Dooley J, Linterman MA, Pierson W, Ucar O, Kyewski B, et al. The thymic epithelial microRNA network elevates the threshold for infection-associated thymic involution via miR-29a mediated suppression of the IFN-alpha receptor. Nat Immunol (2011) 13:181-7. doi:10.1038/ni.2193

68. Zuklys S, Mayer CE, Zhanybekova S, Stefanski HE, Nusspaumer G, Gill J, et al. MicroRNAs control the maintenance of thymic epithelia and their competence for T lineage commitment and thymocyte selection. J Immunol (2012) 189:3894-904. doi:10.4049/jimmunol.1200783

69. Ucar O, Rattay K. Promiscuous gene expression in the thymus: a matter of epigenetics, miRNA, and more? Front Immunol (2015) 6:93. doi:10.3389/fimmu. 2015.00093

70. Nedjic J, Aichinger M, Emmerich J, Mizushima N, Klein L. Autophagy in thymic epithelium shapes the T-cell repertoire and is essential for tolerance. Nature (2008) 455:396-400. doi:10.1038/nature07208

71. Milicevic Z, Milicevic NM, Laan M, Peterson P, Kisand K, Scott HS, et al. Ultrastructure of medullary thymic epithelial cells of autoimmune regulator (Aire)deficient mice. Immunol Cell Biol (2010) 88:50-6. doi:10.1038/icb.2009.55

72. Mizushima N, Yamamoto A, Matsui M, Yoshimori T, Ohsumi Y. In vivo analysis of autophagy in response to nutrient starvation using transgenic 
mice expressing a fluorescent autophagosome marker. Mol Biol Cell (2004) 15:1101-11. doi:10.1091/mbc.E03-09-0704

73. Bhattacharya S, Pal K, Sharma AK, Dutta SK, Lau JS, Yan IK, et al. GAIP interacting protein $\mathrm{C}$-terminus regulates autophagy and exosome biogenesis of pancreatic cancer through metabolic pathways. PLoS One (2014) 9:e114409. doi:10.1371/journal.pone.0114409

74. Murrow L, Malhotra R, Debnath J. ATG12-ATG3 interacts with Alix to promote basal autophagic flux and late endosome function. Nat Cell Biol (2015) 17(3):300-10. doi:10.1038/ncb3112
Conflict of Interest Statement: The authors declare that the research was conducted in the absence of any commercial or financial relationships that could be construed as a potential conflict of interest.

Copyright (c) 2015 Skogberg, Telemo and Ekwall. This is an open-access article distributed under the terms of the Creative Commons Attribution License (CC BY). The use, distribution or reproduction in other forums is permitted, provided the original author(s) or licensor are credited and that the original publication in this journal is cited, in accordance with accepted academic practice. No use, distribution or reproduction is permitted which does not comply with these terms. 